\title{
FDG-Positron Emission Tomography and Computed Tomography Scan
}

National Cancer Institute

\section{Source}

National Cancer Institute. FDG-Positron Emission Tomography and Computed

Tomography Scan. NCI Thesaurus. Code C137817.

An imaging procedure that combines FDG PET with a CT scan to overlay activity data onto detailed anatomic images. 